\title{
The value of individual variables of BODE index and GOLD spirometry in stratifying the severity of COPD
}

Wondu Reta ${ }^{*}$, Samuel Tadessa ${ }^{1}$ and Elsah Tegene ${ }^{2}$

*Correspondence: majore04@gmail.com

CrossMark

« Click for updates

'Department of Biomedical science, School of Medicine, Jimma University, Jimma, Ethiopia.

${ }^{2}$ Department of Internal medicine, School of Medicine, Jimma University, Jimma, Ethiopia.

\begin{abstract}
Background: Chronic obstructive pulmonary disease (COPD) is a preventable and treatable disease characterized by partially reversible airflow limitation. BODE index is amultidimensional tool stands as pneumonic composing the four individual variables $\{\mathrm{B}$-the body mass index $(\mathrm{BMI}), \mathrm{O}$-the degree of airway obstruction (post-bronchodilator FEV1\% predicted), D-Dyspnea scale and E- exercise capacity measured by 6 - minute walk distance test (6MWDT) ; giving the total points of 10; divided into four quartiles. It is used to diagnose, grade the severity, evaluate systemic comorbidities, evaluate the response to intervention and predict the mortality due to the disease.

Purpose: To assess the severity of COPD by using BODE index and its individual variables, and GOLD stage; correlate their values to each other and determine their validity in stratifying the severity of COPD.

Patients and methods: A hospital based cross-sectional study was conducted among a sampled 80 consecutive COPD patients visiting chest clinic of Jimma University Medical Center (JUMC) located at Jimma town, South west Ethiopia; from May 18 to August 18, 2017 G.C; and the measurement of all individual variables of BODE index were performed according to the American Thoracic Society (ATS), their results were entered into EPI data (3.1) and exported to SPSS (20) for further analysis. Chi square $\left(\mathrm{X}^{2}\right)$ test, Spearman correlation, kappa measure of agreement, receiver operator characteristic (ROC) and area under curve (AUC) was applied to determine the correlation and validity of variables/tools in grading the severity of the disease.

Results: 80 COPD patients were enrolled in the study, Mean of age (55.1 \pm 13.66$), \mathrm{BMI}(19.98 \pm 3.43)$,

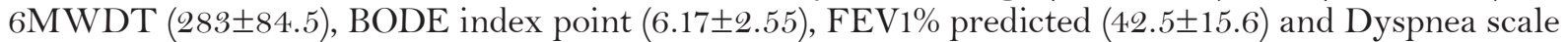
$(2.2 \pm 0.7)$ were achieved. Majority of COPD patients were belonged to quartile IV, relatively increased through the stages if classification was made by BODE index and its components (FEV1\% predicted and 6MWDT) but was higher among stage 3/severe if it was based on GOLD stage and dyspnea score. All variables used to grade COPD were positively correlated with each other except with BMI score (inversely correlated). The validity of the variables/tools used in grading severity of the disease was ranked as BODE index, 6MWDT, FEV1\%, GOLD stage and dyspnea score in descending order while BMI score had the least/poor validity to predict the aim of the study based on specific results of their sensitivity, specificity, AUC with $95 \% \mathrm{CI}$ and p-value.
\end{abstract}

Conclusion: All variables except BMI score were valid to predict severity of COPD.

Keywords: BODE index, BMI, FEV 1\% predicted, Dyspnea scale, 6 MWDT, COPD, GOLD stage

\section{Introduction}

Chronic Obstructive Pulmonary Disease (COPD) is a common preventable and treatable disease with some significant extra pulmonary effects that is characterized by a progressive/persistent airflow limitation, associated with an abnormal inflammatory response of the lungs and airways to noxious particles 
Reta et al. Pulmonology and Respiratory Research 2018,

or gases which is not usually fully reversible [1].

Even though Spirometry $[2,3]$ is used as essential tool for diagnosis and management of COPD based on the severity of air flow limitation expressed in post-bronchodilator result of FEV1\% predicted, but it poorly correlates with patients dyspnea symptoms, quality of life, exacerbation frequency, fatigue and exercise tolerance [4-8]. Thus currently a BODE index which is developed by Celli [9] is recommended for its compressive broad application in diagnosing, grading the severity, evaluating the systemic comorbidities [10], evaluating intervention response $[11,12]$ predicting the mortality [13] and hospitalization $[14,15]$ due to exacerbation of COPD.

The BODE index is a multidimensional instrument that incorporates four main parameters (assessment of the nutritional status by the Body Mass Index (BMI), assessment of the severity of airflow limitation by spirometry result of FEV $1 \%$ predicted, dyspnea scale that assess symptoms of the disease by Modified Medical Research Council (MMRC) and functional status assessment by the 6-minute walk distancetest (6MWD) [9].

\section{Patients and methods Study population}

A cross-sectional study was conducted among sampled 80 consecutive COPD patients visiting chest clinic of Jimma University Medical Center (JUMC) located at Jimma town, South west Ethiopia, from May 18 to August 18, 2017 G.C who diagnosed clinically and by spirometry result of post bronchodilator FEV1 \% predicted, FVC and their ratios as per the guideline of GOLD 2001 [1]. All COPD patients of both gender with different COPD severity available during data collection were included to the study, after verbal and written consent was taken and any patients with unstable comorbidities such as lung cancer, diabetes, heart failure, coronary artery disease, history of congestive heart failure, significant orthopedic or neurological disease, renal, hepatic, or other medical disease that restrict performing the BODE index tests were excluded from the study. The study was approved by the ethical committee of Jimma University review board (IRB/699/2017).

\section{BMI}

Nutritional status was assessed among COPD patients by calculating body mass index (BMI) as one of the component of BODE index which was computed by dividing body weight in kilograms by height in square meters $\left(\mathrm{kg} / \mathrm{m}^{2}\right)$ measured with validated tape meter and weight scale at standing position. Score of BODE index ( 0 and 1 ) was given if $\mathrm{BMI}>21=$ score 0 . If $\mathrm{BMI}<21=$ score 1 [9].

\section{Air flow obstruction}

The degree of airways obstruction was measured by dry digital spirometry (carefusion, Germany) yielding pulmonary function tests (post bronchodilator FEV1\% predicted, FVC, and (FEV1/FVC) ratio for diagnosing and grading the severity of COPD as standardized protocol of ATS guidelines [2,16-18].
FEV1\% predicted result of spirometry in grading the severity of COPD by Celli [9] was somewhat in different from spirometric GOLD COPD stage [2] as explained in Table 1.

Table 1. Summary of GOLD spirometry and BODE index and its component variables scores in grading the severity of COPD.

\begin{tabular}{lllll}
\hline Variables & \multicolumn{4}{c}{ Severity of COPD (Scores) } \\
\hline & $\begin{array}{l}\text { Mild } \\
\text { (0) }\end{array}$ & $\begin{array}{l}\text { Moderate } \\
(\mathbf{1})\end{array}$ & $\begin{array}{l}\text { Severe } \\
(\mathbf{2})\end{array}$ & $\begin{array}{l}\text { Very } \\
\text { severe(3) }\end{array}$ \\
\hline $\begin{array}{l}\text { GOLD stage(Spirometric } \\
\text { FEV1\% predicted) (1,2) }\end{array}$ & $\geq 80$ & $50-80$ & $30-50$ & $\leq 30$ \\
$\begin{array}{l}\text { BODE index (9): } \\
\text { Body-mass index }\end{array}$ & $>21$ & $\leq 21$ & -- & -- \\
FEV1 (\% of predicted) & $>65$ & $50-64$ & $36-49$ & $\leq 35$ \\
$\begin{array}{l}\text { MMRC dyspnea scale } \\
\text { Distance walked in 6 } \\
\text { min (m) }\end{array}$ & $0-1$ & 2 & 3 & 4 \\
\hline
\end{tabular}

Severity of COPD can be categorized as mild/stage I, moderate/stage II, severe/stage III and very severe/stage IV based on GOLD spirometry post bronchodilator $\mathrm{FEV} 1 \%$ predicted result; as $\mathrm{BODE} /$ quartile 1 /score $0, \mathrm{BODE} /$ quartile $2 /$ score $1, \mathrm{BODE}$ /quartile 3 /score 2 and BODE/ quartile $4 /$ score 3 based on points/scores of BODE index.

\section{Dyspnea}

Basal dyspnea scale has been used extensively for grading breathlessness on daily that measures perceived respiratory disability which was assessed using the modified Medical Research Council (MMRC) tools with five items/ dyspnea grades/scales ( 0 minimal to 4 maximum) according to how they perceived their disability $[19,20]$. Scale $0-1=$ score 0 , Scale 2=score 1, Scale 3=score 2, Scale 4=score 3 [9].

Grade 0, "I only get breathless with strenuous exercise";

Grade 1,"I get short of breath when hurrying on the level or up a slight hill";

Grade 2,"I walk slower than people of the same age on the level because of breathlessness or have to stop for breath when walking at my own pace on the level";

Grade 3, "I stop for breath after walking 100 yards or after a few minutes on the level";

Grade 4, "I am too breathless to leave the house/during dressing or undressing".

\section{MWDT}

6MWD was obtained by measuring the total distance the patient walked/ covered in meter within six minutes to evaluate the severity of the disease as the indicator of exercise tolerance capacity of the disease. It was performed as per the ATS guidelines [21]; by which COPD patients were asked to walk at their own pace along a $30 \mathrm{~m}$ long and straight hospital corridor as fast as they could without running, and they were allowed to stop if they developed severe dyspnea, chest pain, dizziness, diaphoresis, or leg cramps during the test. To avoid the confounders (age, sex, weight) 6MWD predicted was calculated by using Enright et al formula [22] 
for both genders as:

Predicted 6MWD $($ male $)=(7.57 x$ height $(\mathrm{cm})-(5.02 \times$ age (year)-(1.76 x weight $(\mathrm{kg})$ - 309m [22]; Predicted 6MWD (female) $=(2.11$ xheight $(\mathrm{cm})-(2.29 x$ weight $(\mathrm{kg})-(5.78 \times a g e)+667 \mathrm{~m}$ [22] . Percent predicted of 6MWD as per Enright et al [22] formula was:

$6 \mathrm{MW}$ D\% predicted=actual 6MWD/ predicted 6MWD $\times 100$. Accordingly $>350 \mathrm{~m}=$ score $0,250-349 \mathrm{~m}=$ score $1,150-249 \mathrm{~m}$ $=$ score $2,<149=$ score 3 [9].

\section{BODE index}

BODE index point was calculated by adding scores of all four individual variables of BODE index (BMI, airway obstruction, dyspnea and exercise capacity). Each variable was categorized on a sore of 0 to 3, except for BMI, which was taken as a dichotomous variable ( 0 or 1$)$. The sum of the variables was yielding a total points of $10(0-10)$, where it grouped into four quartiles to stratify severity of COPD (first quartile/mild corresponding to score $=0$ ( $0-2$ points), the second quartile/ moderate to score $=1$ (3-4 points), the third quartile/severe to score $=2(5-6$ points $)$, and the fourth quartile/very severe to score $=3$ (7-10 points) [9].

\section{Statistical analysis}

Data were coded, entered into epidata 3.1 and analyzed using SPSS 20 (SPSS Inc., Chicago, IL, USA). Data were summarized using mean and standard deviation for continuous variables, numbers and percentage for categorical variables. Comparison between individual bode variables score was done using chisquare test and Correlation statistics was used by spearman's correlation and Cohen'sKappa coefficient of agreement to measure the agreement between the value of BODE index variables in stratifying the severity of COPD. A value of 1 indicates perfect agreement. A value of kappa coefficient of 0 indicates that agreement is no better than chance. Value of $0.01-0.20$ indicates slight agreement, $0.21-0.40$ fair agreement, $0.41-0.60$ moderate agreement, $0.61-0.80$ substantial agreement, and 0.81-0.99 almost perfect agreement [23]. The Spearman correlation coefficient $(r)>0.7$ would indicate the concurrent validity of variable or instrument was reliable [24]. A $p$-value of $<0.05$ was considered to be statistically significant for all. The confidence interval for area under curve (AUC) and receiver operating characteristic (ROC) was computed by the method of DeLong to dictate the predictive validity of individual BODE index variables and GOLD spirometry in stratifying the severity of COPD [25]. Sensitivity and specificity of the tools were reported from the point on the ROC curve.

\section{Results}

\section{Baseline characteristics of COPD patients}

From the total sampled 80 COPD patients attending chest clinic of JUMC from May 18 to August 18, 2017 G.C, the mean age was $55.1 \pm 13.66$ that ranges from $26-90$ years by which majority of them (32.5\%) belongs to interval of 51-60 years with the ratio of males to females of $43 / 37$, of which $63.75 \%$ were experienced smoking. The mean of post-bronchodilator GOLD FEV1\% predicted (42.5 \pm 15.6$)$, BMI (19.98 \pm 3.43$),$ BODE index point (5.22 \pm 2.53$), 6 \mathrm{MWDT}$ predicted $(279 \pm 42.4)$ and MMRC dyspneascale $(2.2 \pm 0.7)$ were computed as detailed in Table 2.

Table 2. Baseline characteristics of COPD patients attending chest clinic of JUMC from May 18 to August 18, 2017 G.C, $n=80$

\begin{tabular}{ll}
\hline Variables & $\begin{array}{l}\text { Mean } \pm \text { standard deviation/ } \\
\text { Number (\%) }\end{array}$ \\
\hline Age in years & $55.1 \pm 13.66$ \\
Sex (M, F), Number (\%) & $43(53.8), 37(46.25)$ \\
Weight in Kg & $53.8 \pm 10.55$ \\
Height in meter & $1.64 \pm 0.089$ \\
Body mass index, kg/m ${ }^{2}$ & $19.98 \pm 3.43$ \\
BMI category (underweight/normal/ & $45 / 27 / 8 / 0$ \\
overweight/obese), Number & \\
FEV1\% predicted & $42.5 \pm 15.6$ \\
Smoking history (exposed/not), & $59(63.75) / 21(36.25)$ \\
Number (\%) & \\
6MWD in meter & $283 \pm 84.5$ \\
6MWD predicted in meter & $279 \pm 42.4$ \\
MMRC Dyspnea scale & $2.2 \pm 0.7$ \\
BODE index point & $6.17 \pm 2.55$ \\
\hline
\end{tabular}

BMI- Body mass index, 6MWD- six minute walk distance, MMRCmodified medical research center, All statistics were presented as mean \pm standard deviation for continuous variables unless stated next to the categorical variable as Number (\%) indicating frequency and percentage.

\section{Severity of COPD}

The GOLD spirometric staging showed that most of studiedpatients were in the GOLD stage III/severe where about 32 patients (40\%) allocated then stage IV/very severe 25(31.25\%), stage II/moderate $20(25 \%)$ and stage $\mathrm{I} /$ mild $3(3.75 \%)$. When using comprehensive BODE index assessment score most of the studied patients were in quartile IV 42 patients $(52.50 \%)$ then quartile II $18(22.50 \%)$, quartile III $13(16.25 \%)$ and quartile I $7(8.75 \%)$. As stated in Table 3 in detail all component variables of BODE index showed the increment of number of patients as severity of the disease advances from mild to very severe except in that of $\mathrm{BMI}$ index score indicating only score $0 /$ mild $30(37.50 \%)$ and score $1 /$ moderate $50(62.50 \%)$ and that of dyspnea score 3 where null patient was observed as very severe stage. The distribution of the severity of the disease by using BODE index variables were: FEV1\% (mild $8.75 \%$, moderate $20 \%$, severe $28.75 \%$, and very severe $42.5 \%$ ), 6MWDT score stage (mild $13.75 \%$, moderate $21.25 \%$, severe $27.50 \%$, and very severe $37.50 \%$ ), dyspnea score stage (mild $3.75 \%$, moderate $31.25 \%$, severe $65 \%$, and very severe $0 \%$ ).

Correlation of GOLD spirometry and BODE index variables in stratifying severity of COPD

BODE index was valid and reliable tool having spearman coefficient $(R>0.7)$ and it had strong association in grading the 
Reta et al. Pulmonology and Respiratory Research 2018,

http://www.hoajonline.com/journals/pdf/2053-6739-6-1.pdf

doi: $10.7243 / 2053-6739-6-1$

Table 3. Severity of COPD based on GOLD spirometry and Belli's BODE index with its component variables among COPD patients attending chest clinic of JUMC from May 18 to August 18, 2017 G.C, n=80

\begin{tabular}{lllll}
\hline \multirow{2}{*}{ Variables } & \multicolumn{3}{c}{ Severity of COPD (Number (\%) } \\
\cline { 2 - 5 } & Mild/Q1(0) & Moderate/Q2(1) & Severe/Q3(2) & Very severe/Q4(3) \\
\hline GOLD Spirometry (FEV1\% of predicted) & $3(3.75)$ & $20(25.00)$ & $32(40.00)$ & $25(31.25)$ \\
BODE index & $7(8.75)$ & $18(22.50)$ & $13(16.25)$ & $42(52.50)$ \\
Body mass index & $30(37.50)$ & $50(62.50)$ & - & - \\
Spirometry (FEV1\% of predicted) & $7(8.75)$ & $16(20.00)$ & $23(28.75)$ & $34(42.50)$ \\
MMRC dyspnea scale & $3(3.75)$ & $25(31.25)$ & $52(65.00)$ & - \\
6MWDT & $11(13.75)$ & $17(21.25)$ & $22(27.50)$ & $30(37.50)$ \\
\hline
\end{tabular}

Severity of COPD can be stratified as mild, moderate, severe and very severe by GOLD COPD stage; as quartiles

(Q1-Q4)/ BODE (1-4) or as scores (0-3) by BODE index with frequency (numbers and percentages) respectively.

severity of the disease with that of GOLD stage of spirometric post bronchodilator result of FEV $1 \%$ predicted score $(\mathrm{R}=0.831$, $\mathrm{K}=0.758 /$ substantial agreement as stated in Table 4 where the correlation was computed by the scores of variables, not by actual values of measured variables), and it was also correlated with its components of FEV $1 \%$ predicted score $(\mathrm{R}=0.828$, $\mathrm{K}=0.631$ /substantial agreement), $6 \mathrm{MWDT}$ score $(\mathrm{R}=0.862$, $K=0.571 /$ moderate agreement), Dyspnea score $(R=0.866$, $\mathrm{K}=0.193$ /slight agreement) and it had no perfect association/ inverse correlation with $B M I$ score ( $R=0.383, K=-0.013$ ).

GOLD stage also had association and it was valid in stratifying severity of COPD with BODE index $(R=0.831, K=0.758)$, FEV1\% ( $R=0.665, K=0.462)$, 6MWDT ( $R=0.725, K=0.5393)$, Dyspnea score $(R=0.652, K=0.120)$ and had no perfect association/ inverse correlation with $\mathrm{BMI}$ score $(\mathrm{R}=0.363, \mathrm{~K}=-0.33)$. BMI score had no perfect association with other scores $\{B O D E$ index $(\mathrm{R}=0.383, \mathrm{~K}=-0.013), \mathrm{GOLD}$ stage $(\mathrm{R}=0.363, \mathrm{~K}=-0.33), \mathrm{FEV} 1 \%$ $(\mathrm{R}=0.142, \mathrm{~K}=-0.039), 6 \mathrm{MWDT}(\mathrm{R}=0.207, \mathrm{~K}=-0.057)$ and Dyspnea score $(R=0.197, K=-0.028)\}$ in grading severity of COPD while others had correlation to each other as displayed in Table 5.

\section{Value of GOLD spirometry and BODE index variables} in stratifying severity of COPD

In general as the value of variables were displayed in ROC
(Figure 1) and AUC (Table 6), the comprehensive BODE index had the highest validity in grading the severity of COPD with $100 \%$ sensitivity, $90 \%$ specificity and AUC of $0.771(0.660-0.883)$ with $p$-value of 0.006 while BMI score had the least validity (sensitivity $67.1 \%$, specificity $56.5 \%$, AUC $0.314(0.137-0.491)$, p-value 0.314 ) in stratifying the degree of the disease.

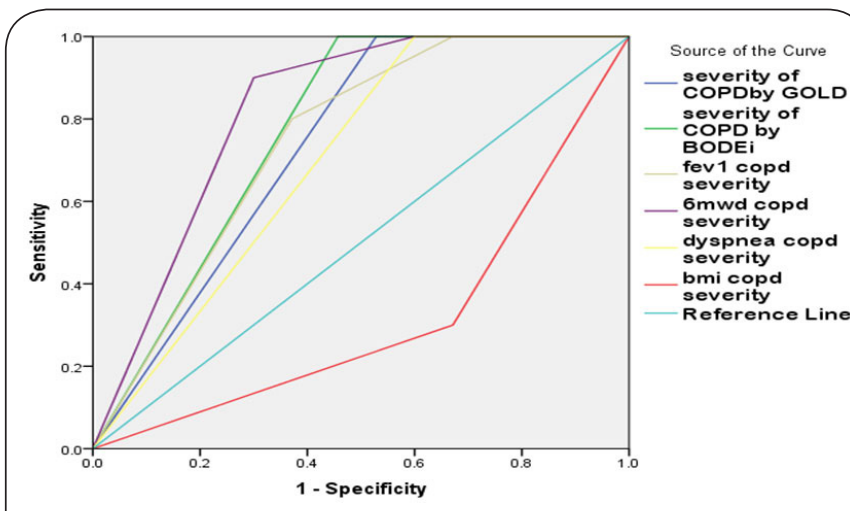

Figure 1. Sensitivity and specificity of GOLD spirometry and BODE index variables in stratifying severity of COPD by ROC among COPD patients attending chest clinic of JUMC

from May 18 to August 18, 2017 G.C, $n=80$.

Table 4. Distribution of COPD Severity based on GOLD spirometry and BODE index criteria among COPD patients attending chest clinic of JUMC from May 18 to August 18, 2017 G.C, $n=80$.

\begin{tabular}{|c|c|c|c|c|c|c|}
\hline \multirow[t]{2}{*}{ Mild } & & \multicolumn{4}{|c|}{ Severity of COPD by GOLD(Number) } & \multirow[t]{2}{*}{ Total } \\
\hline & & Mild & Moderate & Severe & Very Severe & \\
\hline \multirow{5}{*}{$\begin{array}{l}\text { Severity of COPD } \\
\text { by BODE index } \\
\text { (number) } \\
\mathrm{X}^{2}=135.7 \\
\mathrm{p} \text {-value }<0.001^{*} \\
\mathrm{R}=0.831, \mathrm{~K}=0.758\end{array}$} & Quartile1 & 3 & 0 & 4 & 0 & 7 \\
\hline & Quartile2 & 0 & 10 & 3 & 5 & 18 \\
\hline & Quartile3 & 0 & 0 & 13 & 0 & 13 \\
\hline & Quartile4 & 0 & 10 & 12 & 20 & 42 \\
\hline & Total & 3 & 20 & 32 & 25 & 80 \\
\hline
\end{tabular}

$\mathrm{X}^{2}$ - Chi square, ${ }^{*}$-statistical significance, R-Spearman correlation coefficient indicating the association between two ordinal variables (severity of COPD by GOLD and BODE), K- kappa coefficient the measure of agreement of two ordinal variables in grading the severity of COPD as substantial agreement [23]. 
Table 5. Correlation of GOLD spirometry and BODE index variables in grading the Severity COPD among COPD patients attending chest clinic of JUMC from May 18 to August 18, 2017 G.C, $n=80$.

\begin{tabular}{lllll}
\hline Correlated variables & $\mathbf{X}^{2}$ & P-value & Pearson correlation & Kappa \\
\hline BODEindex score by GOLD stage & 135.7 & $<0.001^{\star}$ & 0.831 & 0.758 \\
BODE index score by FEV1\% predicted & 130.3 & $<0.001^{*}$ & 0.828 & 0.631 \\
BODE index score by Dyspnea score & 71.8 & $<0.001^{*}$ & 0.866 & 0.193 \\
BODE index score by 6MWD score & 105.5 & $<0.001^{*}$ & 0.862 & 0.571 \\
BODE index score by BMI score & 18.7 & $0.003^{*}$ & 0.383 & -0.013 \\
GOLD stage by FEV1\% predicted score & 81.6 & $<0.001^{\star}$ & 0.665 & 0.462 \\
GOLD stage by Dyspnea score & 36.6 & $<0.001^{\star}$ & 0.652 & 0.12 \\
GOLD stage by 6MWD score & 59.3 & $<0.001^{\star}$ & 0.721 & 0.393 \\
GOLD stage by BMI score & 13.9 & $0.009^{\star}$ & 0.363 & -0.33 \\
FEV1\% predicted by Dyspnea score & 62.1 & $<0.001^{\star}$ & 0.769 & 0.231 \\
FEV1\% predicted by 6MWD score & 107.9 & $<0.001^{\star}$ & 0.798 & 0.664 \\
FEV1\% predicted by BMI score & 3.36 & 0.35 & 0.142 & -0.039 \\
Dyspnea score by 6MWD score & 48.2 & $<0.001^{*}$ & 0.721 & 0.150 \\
Dyspnea score by BMI score & 3.2 & 0.19 & 0.194 & -0.028 \\
6MWD score by BMI score & 5.98 & 0.13 & 0.207 & -0.057 \\
\hline
\end{tabular}

$\mathrm{X}^{2}$ - Chi square, ${ }^{*}$-statistically significant, all scores of BODE index variables were 0-3 except for BMI score 0-1. (-)-negative kappa coefficient (for BMI score) showed no perfect association/inverse correlationwith other variables. A kappa coefficient $(\mathrm{K})$ as measure of agreement: value 0 indicates that agreement is no better than chance, $0.01-0.20$ indicates slight agreement, $0.21-0.40$ fair agreement, $0.41-0.60$ moderate agreement, $0.61-0.80$ substantial agreement, and 0.81-0.99 almost perfect agreement.The Spearman correlation coefficient $(\mathrm{R})>0.7$ would indicate that the variable was valid in grading the degree of the disease.

Table 6. Area under curve (AUC) indicating Value of GOLD spirometry and BODE index variables in stratifying severity of COPD among COPD patients attending chest clinic of JUMC from May 18 to August 18, 2017 G.C, $\mathbf{n = 8 0}$.

\begin{tabular}{llllll}
\hline Test Result Variable(s) & AUC & P-value & 95\% CI & Sensitivity & Specificity \\
\hline GOLD stage & 0.736 & $0.016^{*}$ & $0.613-0.859$ & 90.0 & 67.1 \\
BODE index & 0.771 & $0.006^{*}$ & $0.660-0.883$ & 100.0 & 90.0 \\
FEV1\% predicted & 0.747 & $0.012^{*}$ & $0.619-0.876$ & 95.7 & 81.4 \\
6MWD score & 0.820 & $0.001^{*}$ & $0.717-0.923$ & 95.6 & 60.0 \\
Dyspnea score & 0.700 & $0.042^{\star}$ & $0.566-0.834$ & 84.3 & 59.0 \\
BMI score & 0.314 & 0.059 & $0.137-0.491$ & 67.1 & 56.5 \\
\hline
\end{tabular}

AUC-area under curve that was used as a criterion to determine the validity of the test. If the test presented with values below 0.7 , they were considered to have low accuracy (BMI score). Values above 0.7 would be considered to be accurate, ${ }^{\star}$ statistically significant.

The dictating value for grading the severity of COPD by using GOLD stage was (sensitivity $90 \%$, specificity $67.1 \%$, AUC 0.736(0.613-0.859), p-value 0.016), FEV1\% predicted (sensitivity $95.7 \%$, specificity $81.4 \%$, AUC $0.747(0.619-0.876)$, p-value 0.012 ), 6 MWD score (sensitivity $95.6 \%$, specificity $60 \%$, AUC $0.820(0.717-0.923), \mathrm{p}$-value 0.001$)$, Dyspnea score (sensitivity $84.3 \%$, specificity $59 \%$, AUC $0.700(0.566-0.834)$, p-value 0.042 ).

\section{Discussion}

Among 80 COPD patients assessed in the present study, their mean age was greater than 50 years $(55.1 \pm 13.66)$ which is in line with other reviewed studies and also supported by GOLD COPD reports [1]. The maximum number of patients were belong to age group 51 to 60 years and maximum were under BODE 3/very severe category by using BODE index classification and its component variables (FEV1\% predicted and 6MWDT) because as the age increases there is physiological decline in lung functions along with exposure to other risk factor for COPD and capacity of concomitant systemic comorbidities [2]. But the maximum patients were grouped in stage III/severe/ by using dyspnea scale and spirometry result of FEV1\% predicted of GOLD COPD staging as it under- 
Reta et al. Pulmonology and Respiratory Research 2018,

http://www.hoajonline.com/journals/pdf/2053-6739-6-1.pdf

doi: 10.7243/2053-6739-6-1

estimates the severity of COPD ignoring to dictate systemic comorbidities (physiological, psychological and exacerbation risk indicators). This was in line with the studies done by B.R Celli et al [9], Kapil KJ et al [26] and Hisham et al [27].

\section{GOLD COPD stage}

Although the result of FEV1\% predicted was used as stand$\mathrm{ard} /$ golden for diagnosing and grading the severity of COPD before 2011 GOLD guidelines, it was poorly correlated with other systemic comorbidities by under estimating the severity of the disease [4-15,26-28]. According to the present study, the severity of COPD was maximum in stage III/severe $40 \%$ then stage IV/very severe $31.25 \%$, stage II/moderate $25 \%$ and minimum in stage $\mathrm{l} / \mathrm{mild} 3.75 \%$ which was in agreement with the studies of Tepetam $M$ et al [28], Jorgen $V$ et al [29] and Hernandes NA et al [30] being grouped in the same fashion through the stages. But in contrast to the present finding majority of the patients were belonged to stage II/moderate by using GOLD stage grading of COPD as showed by result of Kapil KJ et al. (45\%) [26] and Hisham et al. (39.3\%) [27].

In stratifying the degree of COPD, the GOLD stage was correlated with BODE index score as substantial agreement $(\mathrm{R}=0.831, \mathrm{~K}=0.758, \mathrm{P}$ - value $<0.001)$ interpreted as the value of FEV $1 \%$ predicted decreases, there was increment of FEV1 score and resulted in increased stage of COPD. It was also correlated with BODE index component of FEV $1 \%$ predicted score with moderate agreement in grading the degree of COPD $(\mathrm{R}=0.665, \mathrm{~K}=0.462$, $\mathrm{P}$-value $<0.001)$, with 6MWDT score as fair agreement $(R=0.652, K=0.120, P$-value $<0.001)$, with dyspnea score as slight agreement $(\mathrm{R}=0.721, \mathrm{~K}=0.393$, $\mathrm{P}$-value $<0.001)$ and had negative/inverse correlation with $B M I$ score $(R=0.363$, $\mathrm{K}=-0.33$, $\mathrm{P}$-value $=0.009$ ) interpreted as the value of $\mathrm{BMI}$ increases, there was decrement of BMI score and resulted in decreased stage of the disease in opposed to increase FEV1\% predicted score with advanced stage. Although the level of association was not explained in the reviewed studies [26,31-34] the association of GOLD stage in grading the degree of COPD was correlated with that of BODE index score, its components (FEV1\% predicted, dyspnea score and 6MWDT score) was supported with the present study. The correlation of GOLD stage in grading the severity of the disease was in line with our study as statistically evidenced with BODE index score $(R=0.475, P$-value $=0.011)$ [29], with 6MWDT score $(R=0.358$, $\mathrm{P}$-value $<0.003)$ [37] and $(\mathrm{R}=0.524$, $\mathrm{P}$-value $=0.006)$ [38], with dyspnea score $(\mathrm{R}=0.360$, $\mathrm{P}$-value $=0.06)$ [39] with $\mathrm{BMI}$ score $(\mathrm{R}=0.296$, $\mathrm{P}$-value $=0.126)$ [29].

In general GOLD stage that based on FEV1\% predicted score was considered as a valid tool (sensitivity $90 \%$, specificity $67.1 \%$, AUC 0.736(0.613-0.859), p-value (0.016) in grading the severity of COPD.

\section{BODE index}

The BODE index; a multidimensional tool is superior to the GOLD classification for explaining various comorbidities (metabolic, physiological and psychological like anxious and depression) induced with COPD and highly correlated with its degree of the severity of the disease $[9,35]$. It is the most important tool with its domains/parameters in quantifying the degree of pulmonary impairment (FEV1), capturing the patient's perception of dyspnea symptoms by MMRC dyspnea scale, and expressing the consequence of COPD specially by two independent domains (the distance walked in six minutes and BMI). Over all it was currently consumed among researchers and physicians for its broad application of diagnosing, grading, managing and predicting the effect of treatment and prognosis of the disease $[\mathbf{9}, \mathbf{2 6}]$.

According to the BODE index score of COPD severity, majority of the patients were classified in BODE/quartile 4/score $3 /$ very severe (52.5\%) then BODE 2/stage II (22.5\%), BODE 3/ stage III (16.25\%) and BODE 1/stage I (3.75\%). The consistent of more number of patients in quartile 4/stage IV was also observed in other reviewed studies $[\mathbf{9}, \mathbf{2 6}, \mathbf{2 8 , 3 2}]$ as the allocation was made by BODE index than GOLD stage due to its capacity of screening comorbidities within the stages that established in advanced stage of the disease. In our study BODE index was highly correlated with GOLD stage and its components FEV1\% predicted score, 6MWDT score and dyspnea score in the descending order of kappa coefficient measure of agreement in stating the severity of the disease. But it was negatively/inversely correlated with BMI score as majority of the study population were under weight (45\%). Its correlation was also supported by the study of Kapil KJ et al [26] with its three domains ( $P$-value $<0.0001$ ) while its association with $\mathrm{BMI}$ score was not stated.

Generally BODE index was the most valid tool in grading the severity of COPD with its predictive value of $(100 \%$ sensitivity, $90 \%$ specificity, AUC of $0.771(0.660-0.883)$ with p-value of 0.006).

\section{MWDT}

Over the last few years, the use of exercise tests/walking (12MWD/6MWD) has come to be recognized as a convenient method of evaluating respiratory function, reserving the various systems in the human body as it was main activities of daily living [39].

The simplicity, safety, validity, reliability, reproducibility, minimal technological requirement, inexpensive, its correlation with several physiological parameters and broad applications had been in established in different populations $[9,26,39]$. Thus according to result of performed 6MWDT, majority of the patients were classified in BODE score $3(37.50 \%)$, then score $2(27.50 \%)$, score $1(21.25 \%)$ and minimum patients in score $0(13.75 \%)$ where the number of patients increased as severity increases which was against severity classification by NL Nonato et al [40]. 6MWDT score was also correlated with other variables (FEV1\% predicted score, BODE index score, GOLD stage score and dyspnea score in the descending order of kappa coefficient of measure of agreement) while it 
was negatively associated with $\mathrm{BMI}$ score. This correlation of 6MWDT score was also supported with BODE component of FEV1\% [32-34,36-38,41], GOLD stage [31-33,41], Dyspnea score $[32,41]$ and BODE index score ( $p$-value $=0.0001)[26,31]$. As part of BODE index it was also valid in stratifying the severity of COPD with its specific predictive value of (sensitivity $95.6 \%$, specificity $60 \%$, AUC $0.820(0.717-0.923)$, p-value 0.001 ) and also in agreement with the study of Martijn A.S et al [32] reported (sensitivity $77.9 \%$, specificity $77.5 \%$, AUC 0.851 (0.834-0.869) and its validity value of 0.708 [33].

\section{FEV $1 \%$ predicted}

According to the BODE index component of FEV1\% predicted, the COPD patients observed in our study was allocated in BODE score $3(42.50 \%)$, score $2(28.75 \%)$, score $1(20 \%)$ and score $0(8.75 \%)$ and also correlated to GOLD stage score, BODE index and to its components except to BMI score where it inversely correlated; as BMI predicting only score 0 or 1 . It was also valid in stratifying the severity of COPD with its specific predictive value of (sensitivity $95.7 \%$, specificity $81.4 \%$, AUC $0.747(0.619-0.876), \mathrm{p}$-value 0.012 ).

\section{Dyspnea score}

Based on dyspnea score, the severity of the COPD was BODE score $2(65 \%)$, score $1(31.25 \%)$ and score $0(3.75 \%)$ but there was no any patient complained scale 4 dyspnea symptom/ perceived shortness of breath at rest in score 3 using MMRC dyspnea scale tool which was against the result of studies conducted by Kapil KJ et al. (8\%) [26] and NL Nonato et al. (7.5\%) [40] with the observed patients with score 3 respectively. Correlation of dyspnea score in grading the severity of COPD was observed against other variables used except with $\mathrm{BMI}$ score where they inversely correlated. But the inverse correlation of Dyspnea scale with FEV $1 \%$ was stated by R.R Hegde et al. ( $R=-0.514, p$-value $=0.001)$ [42] against our study as the reason for difference was the association performed based on dyspnea scale with FEV1 value and dyspnea score with FEV1\% score whereas the former study stated a highly significant inverse correlation found between MMRC scale of dyspnea and FEV1\%, i.e. as the scale of dyspnea increases, the FEV1 decreases opposing positive correlation between two scores ( $R=0769, K=0.231$, $P$-value $<0.001)$. The usage of Dyspnea score in grading severity of COPD and its correlation with other spirometric parameters was explained by Tepetam $M$ et al [28] and Hajiro et al [43] that the level of dyspnea was more discriminating and controversial. Dyspnea score has an advantage that MMRC is simple and easy to understand for the patients where it can be used as complementary to FEV1 in staging COPD with disability $[\mathbf{2 8 , 4 4 ]}$ and according to our study it was valid with (sensitivity $84.3 \%$, specificity $59 \%$, AUC $0.700(0.566-0.834)$, p-value 0.042).

\section{BMI score}

In our study majority of the patients were belonged to under- weight BMI category (45\%) then normal $27 \%$ and overweight $8 \%$ confirming the more prevalence of COPD among underweight patients. Nutritional depletion is a frequent finding among patients with advanced stage $[26,45]$. BMI is an independent prognostic factor in COPD with a clear association between decreasing body mass and increasing mortality as severity advanced where gain in body weight improves the prognosis of the disease [29]. According to BMI score grading the degree of COPD, $62.5 \%$ of patients who had $B M l<21$ belonged to BODE score 1 while the remaining $31.5 \%$ was in score 0 . The association of BMI score with other variable resulted inverse correlation as it stated only two stages while others grade severity of COPD into four quartiles.

\section{Conclusion}

The majority of COPD patients were belonged to quartile IV, relatively increased through the stages if classification was made by BODE index and its components (FEV1\% predicted and 6MWDT) but was higher among stage $3 /$ severe if it was based on GOLD stage and dyspnea score. All variables used to grade COPD was positively correlated with highest association between BODE index and GOLD stage, FEV1\% and 6MWDT, BODE index and FEV1\%, and BODE index and 6MWDT while inverse correlation was observed between $\mathrm{BMI}$ and other remaining variables. The validity of the variables/tools used in grading severity of the disease was ranked as BODE index, 6MWDT, FEV1\%, GOLD stage and dyspnea score in descending order while BMI score had the least/poor validity to predict the aim of the study.

\section{Competing interests}

The authors declare that they have no competing interests.

Authors' contributions
\begin{tabular}{|l|c|c|c|}
\hline Authors' contributions & WR & ST & ET \\
\hline Research concept and design & $\checkmark$ & $\checkmark$ & $\checkmark$ \\
\hline Collection and/or assembly of data & $\checkmark$ & -- & -- \\
\hline Data analysis and interpretation & $\checkmark$ & -- & -- \\
\hline Writing the article & $\checkmark$ & -- & -- \\
\hline Critical revision of the article & $\checkmark$ & $\checkmark$ & $\checkmark$ \\
\hline Final approval of article & $\checkmark$ & $\checkmark$ & $\checkmark$ \\
\hline Statistical analysis & $\checkmark$ & -- & -- \\
\hline
\end{tabular}

\section{Acknoledgement}

First of all I would like to thank Jimma University (JU) to allow me to conduct this study and provided me with all required materials including financial support. My gratitude also goes to Samuel Tadesse, Elsah Tegene and Sifan Likisa for their incredible role for the success of this paper. At last but not least, my honored thanks go to the data collectors Sr. Fantu, Sr. Worke, Sr. Saliya and Major $\mathrm{G}$. as well as all COPD patients who participated in the study.

\section{Publication history}

Senior Editor: Basil O. Ibe, Harbor-UCLA Medical Center, USA.

Received: 06-Jun-2018 Final Revised: 24-Jul-2018

Accepted: 23-Aug-2018 Published: 07-Sep-2018 
Reta et al. Pulmonology and Respiratory Research 2018,

\section{References}

1. Pauwels RA, Buist AS, Calverley PM, Jenkins CR and Hurd SS. Global strategy for the diagnosis, management, and prevention of chronic obstructive pulmonary disease. NHLBI/WHO Global Initiative for Chronic Obstructive Lung Disease (GOLD) Workshop summary. Am J Respir Crit Care Med. 2001; 163:1256-76. | Article | PubMed

2. Global Initiative for Chronic Obstructive Lung Disease, Global strategy for the diagnosis, management, and prevention of chronic obstructive pulmonary disease. 2011. | Website

3. Mannino DM, Buist AS, Petty TL, Enright PL and Redd SC. Lung function and mortality in the United States: data from the First National Health and Nutrition Examination Survey follow up study. Thorax. 2003; 58:388-93. | Article | PubMed Abstract | PubMed FullText

4. Kerstjens HA. The GOLD classification has not advanced understanding of COPD. Am J Respir Crit Care Med. 2004; 170:212-3; discussion 214. | Article I PubMed

5. Hajiro T, Nishimura K, Tsukino M, Ikeda A, Oga T and Izumi T. A comparison of the level of dyspnea vs disease severity in indicating the health-related quality of life of patients with COPD. Chest. 1999; 116:1632-7. | Article | PubMed

6. Miravitlles $M$, Anzueto $A$, Legnani $D$, Forstmeier $L$ and Fargel M. Patient's perception of exacerbations of COPD--the PERCEIVE study. Respir Med. 2007; 101:453-60. | Article | PubMed

7. Jones PW. St. George's Respiratory Questionnaire: MCID. COPD. 2005; 2:75-9. | PubMed

8. Agusti A and Soriano JB. COPD as a systemic disease. COPD. 2008; 5:1338. | Article | PubMed

9. Celli BR, Cote CG, Marin JM, Casanova C, Montes de Oca M, Mendez RA Pinto Plata $V$ and Cabral HJ. The body-mass index, airflow obstruction, dyspnea, and exercise capacity index in chronic obstructive pulmonary disease. N Eng/ J Med. 2004; 350:1005-12. | Article | PubMed

10. Marin JM, Cote CG, Diaz O, Lisboa C, Casanova C, Lopez MV, Carrizo SJ, Pinto-Plata V, Dordelly LJ, Nekach $\mathrm{H}$ and Celli BR. Prognostic assessment in COPD: health related quality of life and the BODE index. Respir Med. 2011; 105:916-21. | Article | PubMed

11. Imfeld S, Bloch KE, Weder W and Russi EW. The BODE index after lung volume reduction surgery correlates with survival. Chest. 2006; 129:873-8. | Article | PubMed

12. Cote $C G$ and Celli BR. Pulmonary rehabilitation and the BODE index in COPD. Eur Respir J. 2005; 26:630-6. | Article | PubMed

13. Martinez FJ, Foster G, Curtis JL, Criner G, Weinmann G, Fishman A, DeCamp MM, Benditt J, Sciurba F, Make B, Mohsenifar Z, Diaz P, Hoffman $E$ and Wise R. Predictors of mortality in patients with emphysema and severe airflow obstruction. Am J Respir Crit Care Med. 2006; 173:132634. | Article | PubMed Abstract | PubMed FullText

14. Ong KC, Earnest A and Lu SJ. A multidimensional grading system (BODE index) as predictor of hospitalization for COPD. Chest. 2005; 128:3810-6. | Article | PubMed

15. Donaldson GC, Seemungal TA, Bhowmik A and Wedzicha JA. Relationship between exacerbation frequency and lung function decline in COPD. Thorax. 2002; 57:847-852. | Article

16. Laszlo G. Standardisation of lung function testing: helpful guidance from the ATS/ERS Task Force. Thorax. 2006; 61:744-6. | Article | PubMed Abstract | PubMed FullText

17. Miller MR, Crapo R, Hankinson J, Brusasco V, Burgos F, Casaburi R, Coates $A$, Enright $P$, van der Grinten CP, Gustafsson P, Jensen $R$ and Johnson $\mathrm{DC}$ et al. General considerations for lung function testing. Eur Respir J. 2005; 26:153-61. | Article | PubMed

18. Lung function testing: selection of reference values and interpretative strategies. American Thoracic Society. Am Rev Respir Dis. 1991; 144:1202-18. | Article | PubMed

19. Bestall JC, Paul EA, Garrod R, Garnham R, Jones PW and Wedzicha JA. Usefulness of the Medical Research Council (MRC) dyspnoea scale as a measure of disability in patients with chronic obstructive pulmonary disease. Thorax. 1999; 54:581-6. | Article | PubMed Abstract | PubMed FullText
20. Mahler DA and Wells CK. Evaluation of clinical methods for rating dyspnea. Chest. 1988; 93:580-6. | Article | PubMed

21. ATS statement: guidelines for the six-minute walk test. Am J Respir Crit Care Med. 2002; 166:111-7. | Article | PubMed

22. Enright $P L$ and Sherrill DL. Reference equations for the six-minute walk in healthy adults. Am J Respir Crit Care Med. 1998; 158:1384-7. | Article I PubMed

23. Landis JR and Koch GG. The measurement of observer agreement for categorical data. Biometrics. 1977; 33:159-74. | PubMed

24. Swets JA. Measuring the accuracy of diagnostic systems. Science. 1988; 240:1285-93. | Article | PubMed

25. DeLong ER, DeLong DM and Clarke-Pearson DL. Comparing the areas under two or more correlated receiver operating characteristic curves: a nonparametric approach. Biometrics. 1988; 44:837-45. | PubMed

26. Kapil Kumar Jangid, AshwinSongara, NikhileshPasari, Vandana Sharma and Tapas RanjanBahera. Evaluation of Bode Index in prognosis and follow up of COPD patients. International Journal of Research in Health Sciences. 2016; 4:43-50.

27. Hisham El-Said Abdel-Aaty, Mohammed AttiaZamzam, NouraneYehiaAzab, RababAbd El Razek El Wahsh and Samah Ahmed El Beltagy. Comparison of GOLD classification and modified BODE index as staging systems of COPD. Egyptian Journal of Chest Diseases and Tuberculosis. 2014; 63:821-828. | $\underline{\text { Article }}$

28. Tepetam M, Fidan A, Caglayan B, Sarac G, Salepci B and Kiral N. Comparison of dyspnea scoring methods and BODE index with functional parameters in stable COPD. Yeditepe Medical Journal. 2012; 6:567-576. | Pdf

29. Vestbo J, Prescott E, Almdal T, Dahl M, Nordestgaard BG, Andersen T, Sorensen $\mathrm{TI}$ and Lange $\mathrm{P}$. Body mass, fat-free body mass, and prognosis in patients with chronic obstructive pulmonary disease from a random population sample: findings from the Copenhagen City Heart Study. Am J Respir Crit Care Med. 2006; 173:79-83. | Article | PubMed

30. Hernandes NA, Wouters EF, Meijer K, Annegarn J, Pitta F and Spruit MA. Reproducibility of 6-minute walking test in patients with COPD. Eur Respir J. 2011; 38:261-7. | Article | PubMed

31. Pessoa BV, Arcuri JF, Labadessa IG, Costa JN, Sentanin AC and Di Lorenzo VA. Validity of the six-minute step test of free cadence in patients with chronic obstructive pulmonary disease. Braz J Phys Ther. 2014; 18:22836. | Article | PubMed Abstract | PubMed FullText

32. Spruit MA, Watkins ML, Edwards LD, Vestbo J, Calverley PM, Pinto-Plata V, Celli BR, Tal-Singer R and Wouters EF. Determinants of poor 6-min walking distance in patients with COPD: the ECLIPSE cohort. Respir Med. 2010; 104:849-57. | Article | PubMed

33. Carter R, Holiday DB, Nwasuruba C, Stocks J, Grothues C and Tiep B. 6-minute walk work for assessment of functional capacity in patients with COPD. Chest. 2003; 123:1408-15. | Article | PubMed

34. Chen H, Liang BM, Tang YJ, Xu ZB, Wang K, Yi Q, Ou XM and Feng YL. Relationship between 6-minute walk test and pulmonary function test in stable chronic obstructive pulmonary disease with different severities. Chin Med J (Engl). 2012; 125:3053-8. | PubMed

35. Funk GC, Kirchheiner K, Burghuber OC and Hartl S. BODE index versus GOLD classification for explaining anxious and depressive symptoms in patients with COPD - a cross-sectional study. Respir Res. 2009; 10:1. I Article | PubMed Abstract I PubMed FullText

36. Asmita M and Kumari Indira KS. Correlation of Six Minute Walk Test with Spirometry and DLCO in Chronic Respiratory Diseases: a tertiary care hospital experience. Pulmon. 2011; 13:55-58.

37. Agrawal MB and Awad NT. Correlation between Six Minute Walk Test and Spirometry in Chronic Pulmonary Disease. J Clin Diagn Res. 2015; 9:0C01-4. | Article | PubMed Abstract | PubMed FullText

38. Alhamad EH. The six-minute walk test in patients with pulmonary sarcoidosis. Ann Thorac Med. 2009; 4:60-4. | Article | PubMed Abstract I PubMed FullText

39. Morales-Blanhir JE, Palafox Vidal CD, Rosas Romero Mde J, Garcia Castro MM, Londono Villegas A and Zamboni M. Six-minute walk test: 
Reta et al. Pulmonology and Respiratory Research 2018,

a valuable tool for assessing pulmonary impairment. J Bras Pneumol. 2011; 37:110-7. | Article | PubMed

40. Nonato NL, Diaz O, Nascimento OA, Dreyse J, Jardim JR and Lisboa C. Behavior of Quality of Life (SGRQ) in COPD Patients According to BODE Scores. Arch Bronconeumol. 2015; 51:315-21. | Article | PubMed

41. Al Ameri H. Six minute walk test in respiratory diseases: A university hospital experience. Ann Thorac Med. 2006; 1:16. | Article

42. R.R.Hegde, J.M.Phadtare and N.N Ramraje. Title. Indian Journal of Basic and Applied Medical Research. 2013; 2: 1043-1046.

43. Hajiro T, Nishimura K, Tsukino M, Ikeda A, Oga T and Izumi T. A comparison of the level of dyspnea vs disease severity in indicating the health-related quality of life of patients with COPD. Chest. 1999; 116:1632-7. | Article | PubMed

44. Bestall JC, Paul EA, Garrod R, Garnham R, Jones PW and Wedzicha JA. Usefulness of the Medical Research Council (MRC) dyspnoea scale as a measure of disability in patients with chronic obstructive pulmonary disease. Thorax. 1999; 54:581-6. | Article | PubMed Abstract | PubMed FullText

45. Capelli A, Di Stefano A, Gnemmi I, Balbo P, Cerutti CG, Balbi B, Lusuardi $\mathrm{M}$ and Donner CF. Increased MCP-1 and MIP-1beta in bronchoalveolar lavage fluid of chronic bronchitics. Eur Respir J. 1999; 14:160-5. | Article I PubMed

\section{Citation:}

Reta W, Tadessa S and Tegene E. The value of individual variables of BODE index and GOLD spirometry in stratifying the severity of COPD. Pulmonol Respir Res. 2018; 6:1.

http://dx.doi.org/10.7243/2053-6739-6-1 